\title{
DA PRÁTICA DO ENSINO À PRÁTICA DE ENSINO: OS SENTIDOS DA PRÁTICA NA FORMAÇÃO DE PROFESSORES NO BRASIL DO SÉCULO XIX
}

\author{
Shirlei Terezinha Roman Guedes1 \\ shirleirguedes@gmail.com \\ Analete Regina Schelbauer2 \\ analeteregina@yahoo.com.br \\ Universidade Estadual de Maringá - UEM
}

\section{RESUMO:}

Este artigo foi elaborado a partir da pesquisa desenvolvida no Programa de Pós-Graduação em Educação, na Universidade Estadual de Maringá acerca da constituição histórica da Prática de Ensino e sua importância na formação de professores. A Prática do Ensino como modalidade de formação de professores foi no século XIX, uma maneira de preparar o professor primário, mesmo depois da criação da Escola Normal em seus primeiros anos. Por duas ocasiões, no período do Império, a legislação oficializou a formação por meio da Prática do Ensino. Nessas legislações, a formação do professor aconteceria por meio do conhecimento prático do Método de Ensino Mútuo, ou sob a forma de professoresadjuntos. Essa modalidade de formação, em que a prática é o ponto de partida, foi implantada para suprir a necessidade de professores em um período em que as escolas normais ainda não haviam sido criadas ou as mesmas eram abertas e fechadas por falta de alunos. Com a consolidação da Escola Normal como lócus de formação do professor a partir da década de 70 do século XIX e, sobretudo, após a implantação do regime republicano, a Prática de Ensino passou a ser realizada na Escola Anexa ou Escola Modelo, local em que o aluno da Escola Normal aprendia na prática como ser professor. Depois da implantação da Escola Normal, a formação do professor deixou de ser exclusivamente na prática. Sob esta perspectiva, buscamos compreender em que momento e de que forma a Prática de Ensino se configurou e como influenciou a formação de professores na Escola Normal. Abordamos a transição entre a Prática do Ensino e a Prática de Ensino, diferenciando o primeiro modelo como aquele em que a prática acontecia de forma 'artesanal', por meio da convivência, observação e imitação de outro professor. No segundo modelo, a formação do professor estava ancorada nos estudos desenvolvidos na Escola Normal e a prática era desenvolvida na Escola Modelo anexa à Escola Normal. Palavras-chave: Escola Normal, Formação de Professores, Prática de Ensino, Prática do Ensino.

\section{FROM THE PRACTICE OF TEACHING TO TEACHING PRACTICE: THE MEANINGS OF PRACTICE ON TEACHERS FORMATION IN BRAZIL IN THE NINETEENTH CENTURY}

\begin{abstract}
:
This article is based on some researches developed at the Post-Graduate Education from State University of Maringá about the historical development of the Practice of Education and its importance for the teacher formation. The Practice of Teaching as a mode for teacher training, in the nineteenth century, was a way of preparing elementary school teacher, even after the creation of the Normal School in his early years. On two occasions during the period of the Empire, the legislation formalized training through the Practice.
\end{abstract}

Revista HISTEDBR On-line, Campinas, número especial, p. 227-245, mai.2010 - ISSN: 1676-2584 227 
Under those laws, the teacher training would happen through practical knowledge of the mutual teaching method, or as teacher-assistants. That type of training which the practice is the starting point was set up to meet the need of teachers in a period when normal schools had not yet been created or they used to be opened and closed for lack of students. The consolidation of the as a space for teacher training made some difference. That way, from the 70's in the nineteenth century and especially after the implementation of the republican regime, the Practice of Education had to be held at the School or to a School Attached Model. That place was where the student of the Normal School learned in practice to be as a teacher. After the deployment of the Normal School, teacher training is no longer exclusively made in practice. From that perspective, we seek to understand when and how the Teaching Practice is configured and how it influenced the training of teachers at the Normal School. We also discuss the transition between the Practice of Teaching and Teaching Practice, differentiating the first model as one in which the practice took place as a sort of 'craft' thing: through experiences, observation and imitation of another teacher. In the second model, the teacher training was anchored in studies grounded in the Normal School and the practice was developed in the Model School attached to the Normal School. Keywords: Normal School, Teacher Education, Teaching Practice, Practice.

\section{Introdução}

Esse estudo objetiva refletir sobre a construção histórica da Prática de Ensino como uma modalidade de formação, e sua finalidade para a formação do professor no âmbito do Ensino Normal.

A vida de todos os dias embora apaixonante sugere inquietações (Ariès, 1981). Neste sentido, as indagações sobre a constituição histórica da Prática de Ensino impulsionaram nosso olhar ao passado. Trazer o passado não está aqui relacionado a encontrar nele soluções para os problemas atuais. Essa ação permite compreender como os homens, em seu tempo histórico, pensavam e encaminhavam os problemas que os afetavam. No caso da Prática de Ensino, compreender como essa modalidade de formação se organizou se constituiu durante um determinado período, possibilita que possamos ampliar o entendimento que constituímos sobre ela no tempo presente.

O estudo compreendido entre 1827, que marca a Lei da Escola de Primeiras Letras3, e 1889, o advento da República, favoreceu algumas ponderações e reflexões acerca da Prática de Ensino. É possível, ao conhecer o quadro da formação de professores do referido período, afirmar que a formação por meio da prática, marcou, decisivamente, a história da formação do professor antes e depois da instalação da Escola Normal.

O recorte espacial não abrange um local específico, embora os estudos se concentrem nas Províncias/Estados de São Paulo e Rio de Janeiro. O olhar para espaços diferenciados pode possibilitar a compreensão das relações de pertinência, permanência e influência de determinados pensamentos e convicções.

Como estudamos documentos que se referem a um período de tempo passado, é preciso ter cuidado para não olhar para essas fontes com olhar impregnado do presente (HOBSBAWN, 1998). É necessário, portanto, compreender o movimento da história e procurar analisá-los em seu tempo e contexto.

Nesse caso, é preciso compreender o movimento da história para aprender a ler as fontes, sejam elas documentais ou da historiografia. Torna-se necessário o olhar para as mudanças históricas, já que elas desenham as inflexões que aparecem nos documentos. Dessa forma, é preciso manter um olhar para os documentos e outro para a história. 
Entendemos que "[...] as fontes estão na origem, constituem o ponto de partida, a base, o ponto de apoio da construção historiográfica que é a reconstrução, no plano do conhecimento, do objeto histórico estudado" SAVIANI (2004, p. 5). Nesse sentido, selecionamos fontes documentais, primárias e secundárias, da História da Educação Brasileira.

\section{A formação do professor}

A prática, o praticar imitativo foi, durante algum tempo, um dos dispositivos utilizados na formação do professor antes mesmo da instalação das primeiras Escolas Normais na primeira metade do século XIX. Consideramos aqui como formação prática aquela vinculada a observação e imitação de outro professor. Instituída como dispositivo de formação do professor, com tentativas de ser institucionalizada pela legislação, a prática do Ensino foi largamente utilizada como modalidade de formação do professor primário.

Nessa perspectiva foi necessário atribuir à Prática do Ensino uma função específica, ou seja, considerá-la como modalidade de formação, campo de saber na estrutura curricular dos cursos de formação de professores. Buscamos compreender sua estrutura e função mesmo antes de ser uma disciplina no currículo da Escola Normal. Com o intuito de dar organicidade e sentido ao objeto de estudo, de agora em diante, passaremos a abordar o tema sob duas denominações: Prática do Ensino e da Prática de Ensino.

Consideramos como Prática do Ensino todas as expressões de formação do professor não vinculadas à Escola Normal, ou seja, antes de sua criação, como dispositivo para a formação do professor. A preparação do professor estava vinculada à observação, convivência e imitação de atividades de ensino, sem, contudo, vincular-se a uma formação escolarizada.

A Prática de Ensino, delimitada neste estudo, passa a acontecer com a criação das Escolas Normais. Nesse caso, a formação prática do professor, de início, ainda vinculada à observação e imitação, ganha um espaço específico e passa a receber algumas normatizações: os dispositivos da demonstração e depois de experimentação, que a diferenciam do modelo denominado aqui como Prática do Ensino.

Com base nessa prerrogativa objetiva-se conhecer em que momento e com que configuração a Prática de Ensino foi instituída nos cursos de formação de professores? Houve mudanças no encaminhamento da Prática do Ensino? Quais foram as principais idéias que influenciaram a Prática de Ensino?

Podemos entender que a formação do professor, em alguns momentos históricos, esteve baseada no "saber provindo da experiência", ou seja, por meio do contato com o trabalho de um professor já experiente e atuante, se aprenderia como ensinar. A observação do trabalho de um professor em sala de aula possibilitaria a vivência e os conhecimentos necessários para aprender a função de professor.

Nesse sentido, aprender a ser professor estava relacionado com a observação, convivência e imitação. O modelo "artesanal4" de formação, em que aprender está relacionado à imitação de modelos, foi uma maneira de formar o professor brasileiro. Essa maneira, baseada na aprendizagem do Método Mútuo ou por meio dos professores adjuntos, marcou a formação de professores no Brasil no século XIX, antes e depois da criação da Escola Normal.

Ao levar em consideração o modelo "artesanal" de formação do professor, verificamos que era considerado importante nessa formação: o conhecimento dos conteúdos a serem ensinados aos alunos e a maneira de ensiná-los, baseada em observação, convivência e imitação. Por isso, o candidato a professor, durante certo tempo, permanecia

Revista HISTEDBR On-line, Campinas, número especial, p. 227-245, mai.2010 - ISSN: 1676-2584 229 
em contato com um professor já atuante com o objetivo de aprender a ser professor. Aprender a ensinar, portanto, era o foco da preparação do professor.

A formação do professor passou por alterações com a criação da Escola Normal. Na verdade, institui o local específico para essa formação e, em nosso entendimento, marca o início da profissionalização da profissão. Como local específico, apresentava uma estrutura e organização própria, embora muito elementar para os parâmetros atuais, tinha proposta e intenção de formar o professor.

As primeiras Escolas Normais, criadas a partir de 1835, como é o caso da Escola Normal da Província do Rio de Janeiro, e, outras como: Minas Gerais, 1835, (instalada em 1840); na Bahia em 1836 (instalada em 1841); em São Paulo em 1846; em Pernambuco e no Piauí em 1864 (ambas instaladas em 1865); em Alagoas em 1864 (instalada em 1869); em São Pedro do Rio Grande do Sul em 1869; no Pará em 1870 (instalada em 1871); no Amazonas em 1872, embora já em 1871 tivesse sido criada uma aula de Pedagogia no Liceu; no Espírito Santo, em 1873; no Rio Grande do Norte, em 1873 (instalada em 1874); no Maranhão em 1874, foram tentativas improvisadas, criadas por decreto e fechadas por falta de condições. Isso pode ter acontecido devido a vários fatores, inclusive a própria legislação que não previa a necessidade de formação institucional para o professor, ou, ainda, falta de estrutura e perspectivas profissionais para o professor primário.

Nessas escolas, o currículo tinha como preocupação ensinar o conteúdo que os professores lecionavam nas escolas de primeiras letras. Essa maneira de compreender a formação do professor reduziu, ou como expressa Tanuri (2000), marcou a escola Normal com um ensino apoucado, estreitamente limitado em conteúdo.

A Prática do Ensino, nesse contexto, era realizada em escolas primárias local onde o futuro professor aprenderia, com outro, as questões necessárias para atuar em uma sala de aula. As "atividades práticas de ensino", desenvolvidas na Escola Primária, eram responsáveis pela formação prática do professor que era o foco do processo.

Os conteúdos que o professor deveria ensinar na Escola Primária eram aprendidos, juntamente, com a maneira de ser professor. Dessa forma, a frequência à Escola Normal parecia desnecessária.

A criação da Escola Normal, na Europa, está vinculada à criação dos Estados Nacionais e à institucionalização da instrução pública no mundo moderno. Embora as raízes da Escola Normal remontem ao período da Reforma e Contra Reforma, com as experiências de formação de professores de Jean Baptiste de La Salle, foi com a Revolução Francesa que ela se efetivou como instituição pública, laica e destinada à formação de professores.

No Brasil, a defesa da Escola Normal, como lócus de formação, existiu durante o período do Império. Entretanto seu funcionamento foi irregular. Embora a Escola Normal tivesse sido difundida como caminho para organizar a instrução do povo, ela não foi implantada com prestígio, não gerou interesse imediato da população. Isso pode ser explicado também porque

[...] a questão da formação de professores irá exigir uma resposta institucional apenas no século XIX quando, após a Revolução Francesa, se coloca o problema da instrução popular. É daí que deriva o processo de criação de escolas normais, como instituições encarregadas de preparar professores (SAVIANI, 2005, p. 1).

Além disso, algumas condições que se estabeleciam no país não favoreciam que a Escola Normal fosse alvo de interesse por parte da população. Fatores como o salário dos professores, o esquema de contratações, o valor maior atribuído ao aprender na prática do

Revista HISTEDBR On-line, Campinas, número especial, p. 227-245, mai.2010 - ISSN: 1676-2584 230 
que à formação institucional, entre outros, não estimulavam o acesso dos alunos à Escola Normal.

No período do Império, tal como a escola de primeiras letras, a Escola Normal era responsabilidade e competência das Províncias, ou seja, a implantação e organização ficavam no limite de cada Província. Saviani (2005, p. 2) explicita que

com a descentralização processada pelo Ato Adicional à Constituição Imperial de 1823, aprovado em 1834, o ensino elementar ficou sob a responsabilidade das províncias que, em consequiência, também deveriam cuidar do preparo dos respectivos professores.

A descentralização abriu caminho para que cada Província organizasse a instrução Pública e a formação do professor. Assim, logo após o ato adicional de 1834, a Província do Rio de Janeiro implantou a primeira Escola Normal do Brasil5.

A criação da primeira Escola Normal do Rio de Janeiro foi anuncida pelo, então, Presidente da Província, Conselheiro Joaquim José Rodrigues Torres, ao abrir a $1^{\text {a }}$ sessão da $1^{\text {a }}$ Legislatura da Assembleia legislativa em 01 de fevereiro de 1835, como uma das possibilidades de melhorar a instrução pública.

Parece-me, Senhores, que a creação temporaria de huma escola normal, onde se podessem habilitar convenientemente, não so os Candidatos ás Cadeiras vagas, mais ainda os actuaes Professores que disso carecessem, fôra, além da outra medida acima indicada, e do indispensavel argumento de honorarios aos professores, remedio poderoso para dar á Instrucção Publica os melhoramentos, que ella reclama (FALA DO PRESIDENTE DA PROVÍNCIA, 1835, p. 3).

As palavras do Presidente da Província demonstram a perspectiva de formação de professores, institucionalizada pela Escola Normal, como condição necessária para melhorar a instrução pública. Ao grupo dirigente da Província do Rio de Janeiro, liderado pelo Presidente Conselheiro Joaquim José Rodrigues Torres e Vice-Presidente Paulino José Soares de Souza, coube a implantação dessa primeira Escola Normal do Brasil.

Esse grupo, a princípio pertencente ao partido liberal, migrou para o conservador por causa de conflitos internos. Dessa forma, foi o partido conservador que imprimiu suas idéias naquele momento. Assim, a Escola Normal da Província do Rio de Janeiro foi criada com a função de "formar o professor como agente transmissor da ideologia desse Estado que se organizava" (VILLELA, 1992, p. 28).

Entretanto as Escolas Normais instaladas e fechadas em curtíssimo período, levaram o Presidente da Província do Paraná, Polidoro Cezar Burlamaque (1836-1894)6, em meados do século XIX, a chamá-las de "[...] plantas exóticas; nascem e morrem quase no mesmo dia7" (RELATÓRIO, 1867).

Embora as primeiras Escolas Normais não tivessem conseguido cumprir seu intento, na escola do Rio de Janeiro pode-se visualizar, entre 1860 a 1880, nova perspectiva na formação do professor primário. Formar o professor com melhores condições para ensinar às crianças que aquelas apresentadas pelo antigo mestre escola, foi a tônica da gestão de José Carlos de Alambary Luz, na Escola Normal de Niterói no período entre 1868 e 1876 (VILLELA, 2003). Nesse período, a estrutura da Escola Normal estava mais definida, em relação ao Currículo e aos Métodos. Verificamos que a mesma estava mais preocupada com o que ensinar aos futuros professores e 
o debate em torno do Método Intuitivo ganhou expressão como parte do movimento de escolarização das classes populares, num momento em que encontrar os meios para uma escolarização inicial eficaz se constituía numa das maiores preocupações daqueles que estavam envolvidos na organização dos sistemas nacionais de ensino (SCHELBAUER, 2006, p. 2).

No que se refere à formação do professor no final do século XIX, ao estudar o processo de institucionalização da escola Normal do Rio de Janeiro, Villela (2003) estabeleceu quatro hipóteses. A primeira hipótese8, que nos interessa especialmente neste artigo, é que no período de 1860 a 1880, a Provincia do Rio de Janeiro viveu uma nova experiência, ou seja,

[...] a substituição do modelo 'artesanal' de formação de professores, baseado na tradição e imitação característica da cultura pragmática, pelo modelo profissional, baseado no critério da racionalidade em que conhecimentos teóricos e prática profissional acontecem em lugares distintos e pressupõem um alargamento do conteúdo acadêmico, domínio de métodos específicos e aquisição de ethos condizente com a profissão (VILLELA, 2003, p. 1).

Tomando como referência essas questões, é necessário trazer para nossa discussão alguns aspectos que estiveram presentes na formação de professores no modelo "artesanal". Um deles é o aprender a ser professor por meio da observação e imitação da prática dos professores de primeiras letras foi o dispositivo que prevaleceu na formação de professores durante o Império no Brasil e foi sugerido para a formação do professor nas Escolas de Ensino Mútuo9, instituídas pela Lei de 1827 e com a tentativa de instituição dos professores adjuntos na Reforma Coutto Ferraz de 1854. Após a criação da Escola Normal, a formação prática assumiu diferentes formas e concepções.

\section{A formação prática nas escolas de Ensino Mútuo}

No período anterior à 1808 que marca a chegada de D. João ao Brasil, a educação encontrava-se em situação muito difícil. As iniciativas para garantir a instrução do povo e a formação de professores não tinham uma diretriz institucional sobre a sua organização.

Diante do quadro de problemas, depois de instalar-se, D. João incumbiu o Ministro Antonio de Araújo e Azevedo - Conde da Barca (1754-1817) em estudar os princípios do sistema lancasteriano de educação para dar unidade às escolas e à educação do povo. Dessa forma, podemos afirmar que as idéias acerca do ensino mútuo10 foram introduzidas no Brasil a partir de 1808 e foram oficializadas com a Lei de 1827 (BASTOS, 1999a, 1999b; ALMEIDA, 200011; SAVIANI, 2007).

Somente depois de 1820, depois da expulsão dos jesuítas, foram criadas as escolas de Ensino Mútuo, com a preocupação de ensinar não apenas as primeiras letras como também preparar professores, instruindo-os no domínio do Método de Ensino Mútuo.

As nossas primeiras escolas de Ensino Mútuo estavam ligadas ao Corpo Militar do Governo Imperial. Em relação a essa questão, em $1^{\circ}$ de março de 1821 , foi criada uma Escola de Ensino Mútuo no Rio de Janeiro e, no ano seguinte, 1822, "uma ordem ministerial de 29 de abril [...] exigiu de cada província do Império o envio de um soldado 
que seguiria as lições dessa escola a fim de aprender aí o método para, em seguida, propagá-lo na província de origem" (ALMEIDA, 2000, p. 57).

De fato, podemos constatar que essas medidas promoveram, por algum tempo, o recrutamento de professores nos quadros do exército12. O que nos interessa, aqui, é compreender o motivo do recrutamento de professores entre os militares identificava o potencial disciplinador do ensino mútuo. Nessa perspectiva, disciplinar, desenvolver hábitos de hierarquia e ordem tinha maior importância do que instruir. Para isto, não havia melhores professores do que os militares para cumprir essa função. Dessa forma, o grupo conservador poderia continuar com os propósitos políticos de ordem e civilização, ou seja, manter a sociedade hierarquizada e o trabalho escravo, que possibilitava garantir à classe senhorial a propriedade e o poder.

Foi na perspectiva lancasteriana que o Método foi implantado no Brasil. Neves (2003) constatou13 a apropriação brasileira do Método e sua aproximação maior com as idéias de Lancaster. Essa forma de ensinar, em que o monitor torna-se a principal figura, possibilita que se possa supor que a escola que foi organizada para instrução do exército também formou professores. Essa "escola" não tinha as mesmas características da Escola Normal entretanto, tornou-se centro difusor do método e o ensinava às pessoas que estavam interessadas em aprender essa maneira de ensinar as crianças.

No ensino mútuo, um professor instruía os monitores para que estes atendessem aos demais alunos da classe. O professor ensinava o método, treinava os monitores para conduzirem os outros alunos. Dessa forma, se considerada como uma iniciativa de formação de professores, assim se apresenta o que chamamos de formação na prática ou treinamento em serviço: ao mesmo tempo, o aluno atuava como monitor, e era treinado para o ofício de mestre.

Esse dispositivo parecia resolver o problema da formação de professores e da implantação de escolas. Atendia à necessidade da população e resolvia o problema da falta de professores.

É o que podemos entender pelo teor do Decreto de 15 de outubro de 1827 que determinou a criação de escolas de primeiras letras em todas as cidades, vilas e lugares mais populosos do Império. Essa legislação é, na verdade, um marco na história da educação brasileira. Inicia a presença do Estado na organização da Educação. Promulgada por D. Pedro I, objetivava organizar e difundir a instrução, fiscalizar as escolas, propor um método para ensinar e encontrar mestres com as aptidões necessárias ao exercício da profissão. Estabelecia a proposta de exames para seleção de mestras e mestres, ainda sem considerar a formação em local específico14. Era solicitado ao candidato o conhecimento do método mútuo.

Entretanto, se o candidato a professor não estivesse preparado, o documento recomendava que buscasse sua preparação em curto prazo nas escolas de ensino mútuo das capitais. Nesse caso, um professor de primeiras letras que conhecia o método mútuo se encarregava de preparar outros professores, dispensando, com isso, a criação e manutenção de cursos específicos para esse fim.

A necessária preparação nas escolas de ensino mútuo, a preparação em curto prazo, por meio de demonstração prática, mostram como era entendida a formação do professor. Saber para ensinar. Saber aquilo que precisa ser ensinado. Nessa perspectiva, preparar o professor era ensinar o método.

Os monitores, futuros professores, para alcançarem o título de mestre, eram arguidos por meio de exames realizados pelo Presidente da Província, mais três examinadores pertencentes à academia científica ou pessoas de notório saber. $\mathrm{O}$ conhecimento do conteúdo a ser ensinado era meticulosamente avaliado nos candidatos 
que pretendiam inscrever-se às cadeiras vagas no magistério da província. O Decreto esclarece que a maneira de transmitir as doutrinas seria pelo método lancasteriano, entretanto não especifica se seriam exigidos conhecimentos teóricos acerca do método.

Evidencia-se, por meio do Decreto de 1827, a formação na prática, como recurso encontrado para suprir a falta de professores de primeiras letras. O domínio do método era o conhecimento necessário para que o professor pudesse atuar, ou seja, ensinar. É necessário ressaltar que o conhecimento do método, nessa perspectiva, significava saber a maneira de ser aplicado em sala de aula, sem a necessidade de conhecer as raízes teóricas.

As Escolas de Ensino Mútuo pareciam responder à necessidade de formar novos mestres. Entretanto, à medida que aconteceram as críticas ao Ensino Mútuo e que sua efetivação no território brasileiro não aconteceu, outras iniciativas precisaram ser tomadas. Esses fatos, dentre outros, levaram a outras iniciativas relativas à preparação do professor. Tais iniciativas, no entanto, ainda aconteceram vinculadas ao modelo 'artesanal' de convívio, observação e imitação.

\section{A formação prática e os professores adjuntos}

O modelo de formação em que o futuro professor aprendia, na prática, a ensinar, por meio da atuação como auxiliar de outro professor não favorecia a criação ou fortalecimento da Escola Normal. Nesse modelo, a formação institucional cedia espaço para uma formação cuja referência e base era a atuação de outro professor.

Almeida (2000), ao referir-se à condução da instrução pública no período do Império, alerta que os legisladores votaram inúmeras leis no sentido de promover a instrução pública, porém estas se mostravam incoerentes até mesmo no âmbito da mesma Província.

Autores que escreveram sobre a educação brasileira no final do século XIX e início do século XX analisam que a ausência de uma estrutura que cuidasse da formação ou preparo dos professores foi um dos graves problemas que, aliado a outros ou não, inviabilizaram as reformas pensadas e estruturadas pelos legisladores (ALMEIDA, 2000; VERÍSSIMO, 198515).

Em meio à criação de Escolas Normais que abriam e fechavam por falta de estrutura e alunos, a indefinição pela formação do professor fez nascer um outro modelo: o do professor adjunto. Suprir a necessidade de professores por meio de professores adjuntos foi uma das tentativas da Reforma Coutto Ferraz em 1854. O ministro do Império, Luiz Pedreira do Coutto Ferraz (1818-1886), por meio do Decreto 1.331 A, de 17 de fevereiro de 1854, aprovou o "Regulamento para a reforma do ensino primário e secundário do Município da Corte".

Considerada como uma proposta de regresso e inovação (GONDRA; SACRAMENTO, 2002) marcou a formação do professor por meio da Prática do Ensino. A centralização das intervenções, proposta na Reforma estava diretamente ligada ao momento vivenciado pelo Império.

$\mathrm{Na}$ Reforma, entre outras questões, estão expressas: a ausência de monopólio sobre a instrução; obrigatoriedade do ensino elementar; as condições para o magistério público sobre nomeação, demissão e vantagens dos professores, bem como processo disciplinar para faltas; a graduação do ensino; organização de classes pela idade; a normatização da educação feminina e condições para o financiamento da educação.

Prática do Ensino, preparação do professor que previa a convivência, observação e imitação, eis os dispositivos utilizados pelos legisladores para prover a falta de professores e de uma escola adequada, que promovesse essa formação. Dessa maneira, 
[...] como meio de substituir a falta de uma escola normal, o regulamento de 17 de fevereiro de 1854 criou os professores adjuntos para as escolas públicas, uma espécie de monitores remunerados, escolhidos entre os alunos com mais de doze anos de idade, capazes de seguir os exames anuais e demonstrando disposição para o ensino (ALMEIDA, 2000, p. 91).

Entretanto a forma encontrada pelo Regulamento de 1854, para suprir a falta de uma Escola Normal, merece outra explicação. Coutto Ferraz não acreditava muito na eficiência da Escola Normal, considerava-as onerosas e ineficientes quanto à qualidade da formação ali oferecida (SAVIANI 2007, p. 133).

A Lei de 1854 propõe, em seu Capítulo II, a instituição dos "Professores adjuntos16: substituição nas escolas". Os artigos 34, 35 e 36, estabeleciam os dispositivos para a escolha e nomeação desses professores. Especificavam que a classe dos adjuntos seria formada por alunos das escolas públicas, maiores de doze anos de idade que alcançassem distinção nos exames anuais, tivessem bom procedimento e propensão para o magistério.

Assim, "pela via da atuação como auxiliar junto a um professor público em exercício, se buscou formar os novos professores, dispensando-se a instalação de Escolas Normais" (SAVIANI, 2007, p. 133). Nesse contexto, temos a Prática do Ensino por convivência, observação e imitação.

Mesmo conjugando três critérios, conforme o artigo 35, o aproveitamento, o bom procedimento e a propensão para o Magistério, a Reforma Couto Ferraz fazia uma avaliação muito subjetiva dos pretendentes ao cargo de professor. Quanto ao aproveitamento, os exames abrangiam apenas o conhecimento necessário para lecionar nas salas de aula do ensino primário. No caso dos outros dois critérios, o bom procedimento e a propensão ao magistério, as avaliações remetiam ao âmbito da subjetividade. Com isso, parece que não havia necessidade e estímulo ao estudo das ciências pedagógicas para que o professor pudesse ensinar.

Para serem contratados, os professores adjuntos deveriam fazer exames anuais e permaneciam nessa condição durante três anos para mostrar o progresso. Se esse tempo de três anos fosse suficiente, receberiam um título de capacitação que os tornavam aptos a substituir os institutores em seus impedimentos ou serem chamados para os empregos vagos (ALMEIDA, 2000). Sobre a formação prática, o artigo 38 estabelecia que "estes professores ficarão addidos ás escolas como ajudantes, e para se aperfeiçoarem nas matérias e pratica do ensino" (BRASIL, 1854, p. 53).

Imprimiu-se mais uma vez a formação por meio da Prática do Ensino. Essa situação, prevista pelos legisladores, mostra a crença que o conhecimento necessário para a função docente seria adquirido pelo convívio, observação e imitação de um professor atuante.

Embora existisse um longo caminho a ser percorrido pelos adjuntos até o título de mestre, três anos no mínimo, essa formação não tinha estrutura uniforme já que, os futuros professores eram "treinados" para o conhecimento da profissão. A formação ficava assim ao encargo dos professores atuantes, independente do conhecimento que tivessem sobre a mesma.

\section{A transição entre a Prática do Ensino e a Prática de Ensino}

Escolhemos as palavras de Rui Barbosa para ilustrar a discussão que trata da transição entre a Prática do Ensino - modelo "artesanal" - à Prática de Ensino, como 
formação que se distancia do modelo exclusivamente prático e imitativo na formação do professor. A discussão sobre a formação do professor primário, que aconteceu antes da Proclamação da República, fortaleceu a idéia de que não bastava apenas o método. Era necessário que professor estivesse preparado para aplicar esse método. Essa constatação fica evidente nas palavras do jurista.

Nesse sentido, pois, não é menor o preço do mestre que o do método, porque, sem o mestre o método seria apenas uma concepção ideal; porque o método é inseparável do mestre; porque o mestre é o método animado, o método em ação, o método vivo (BARBOSA17, 1883, p. 119)

No sentido de mostrar como aconteceu o processo de transição da Prática do Ensino à Prática de Ensino no período anterior à Proclamação da República, identificamos os indícios que mostram esse novo momento em São Paulo. Educar a população, formar professores por meio de um bom método de ensino, parecia ser o anseio dos dirigentes e educadores. Os debates sobre a educação popular, as discussões acerca da necessidade de métodos e mestres marcam muito bem a ruptura com o modelo "artesanal" de formação de professores.

A criação da Escola Normal e sua consolidação foi fundamental para a transição da Prática do Ensino à Prática de Ensino. Nas primeiras escolas normais a formação prática era realizada em escolas primárias anexas, local em que os alunos da Escola Normal aprendiam, observando o trabalho dos professores atuantes marcam um local específico para a formação prática do futuro professor.

Exercitando a observação poderiam aprender a "arte de ensinar" para depois, segundo os princípios observados, reger sua própria sala de aula. É importante esclarecermos as diferenças existentes entre os dois modelos de formação, para que entendamos a importância da criação da Escola Normal e a instituição da Prática de Ensino nas escolas anexas. Esse encaminhamento demonstra uma nova maneira de preparar o futuro mestre, diferenciando-se dos antigos professores.

Em seu Parecer, Rui Barbosa expressa também a preocupação com a formação do mestre. Essa formação poderia ser definida como um conjunto de saberes, valores, normas e modos de ação, denominado por Villela (2003, p. 4) de "aquisição de uma postura -um ethos- profissional".

A excelência deste reside na sua apropriação perfeita às exigências da lei que o determina, da mesma sorte como a superioridade do educador consiste na adaptação rigorosa do seu espírito aos princípios do método que o guia. $\mathrm{O}$ mestre, o verdadeiro mestre, é uma como encarnação pessoal do método: dependem mutuamente um do outro; e seria mais ou menos igual, de parte a parte, a reciprocidade, se aos requisitos intelectuais que o método impõe, e dirige, não acrescessem, no tipo do educador, as qualidades morais, que não entram no sistema do método, mas a que os frutos deste, em grande parte, estão subordinados (BARBOSA, 1883, p. 120).

Por meio dessa constatação, observamos que se modifica sensivelmente a formação do professor e se vislumbra um sentido para a carreira do professor primário, conferindolhe status, o que não era muito comum na época. Precisamos considerar o período, década de 80 do século XIX, quando os debates sobre a necessidade de ampliação de escolas de primeiras letras destacam a necessidade de mais mestres e de condições profissionais e financeiras para exercer a profissão.

Revista HISTEDBR On-line, Campinas, número especial, p. 227-245, mai.2010 - ISSN: 1676-2584 236 
Como podemos verificar, no período imediatamente anterior à República, um novo olhar para a formação do professor parece despontar. Ganhou espaço a defesa pela formação institucional estruturada e com objetivos definidos. "Estabelecer os melhores métodos, prover do mais complexo material clássico, a todas as escolas, rodear o magistério das mais altas vantagens sociais, tudo será improfícuo e vão, se não organizarmos a educação do mestre" (BARBOSA, 1883, p. 123).

No Parecer de Rui Barbosa, ao discorrer sobre os exercícios práticos, o jurista faz uma rigorosa defesa quanto ao tempo de estudos que o aluno mestre deve dedicar na Escola Normal, para que possa ter tempo "indispensável para os trabalhos práticos na escola anexa" (BARBOSA, 1883, p. 183). Na concepção do autor, os exercícios práticos são fundamentais. Devem ser organizados e ter critérios de realização.

Os exercícios práticos, no plano que traçamos, encontram a mais elevada consideração. Dão começo desde o semestre inicial do primeiro ano, durante o qual os alunos presenciarão os trabalhos da escola anexa, principiando no segundo trimestre a compartir neles, auxiliando-os. Do segundo ano em diante se lhes cometerá, por uma graduação progressiva, a direção de várias classes, para o que serão distribuídos em turma (BARBOSA, 1883, p. 183-184).

Procuramos evidenciar, com as questões apresentadas, os indícios de mudanças quanto à formação do professor primário, especificamente no que se refere à Prática de Ensino.

As escolas primárias anexas contribuíram com a ampliação do horizonte de formação de professores. O Regulamento da Escola Normal de São Paulo de 03/01/1887, no capítulo XVII, especificava que as alunas do primeiro e segundo ano deveriam frequientar as aulas na escola primária anexa. Estas escolas eram destinadas, ao exercício prático do magistério primário pelos alunos da Escola Normal.

Nesse regulamento, podemos verificar que a referência à escola anexa acontece com a indicação do exercício prático das prendas domésticas, realizados no primeiro e segundo ano. Essa prática está relacionada à dupla função que passava a se fazer presente na Escola Normal: "formar mestras de escolas e dar uma instrução geral às mulheres" (VERÍSSIMO, 1985, p. 126).

Em sua obra Veríssimo (1985, p. 129), evidencia que o pensamento vigente dessa época, até por conta da colonização, era que a mulher, como "primeira e imediata educadora do homem", deveria ser bem educada, para que pudesse cumprir, com êxito, a sua função: esposa e mãe. Reconhece a Escola Normal como instrumento de mudança de costumes na educação das moças e possibilidade de "tirar a mulher brasileira da quase ignorância" a que era submetida, primeiro, por seu pai, depois, pelo marido.

Não é de causar espanto que a Escola Normal garantisse em seu currículo o exercício em prendas domésticas. A função de dona de casa e mãe, até então, era a principal atividade da mulher. No entanto, pela necessidade de inserção no mercado de trabalho,

[...] talvez a maior motivação das mulheres tenha sido viabilizar no magistério a oportunidade de um trabalho remunerado. [...]. Ser professora possuía maior notoriedade do que ser governanta ou costureira e, mesmo não sendo bem remunerada, pagava melhor em relação às outras profissões (ALMEIDA, 2006, p. 145). 
A formação em disciplinas como prendas domésticas, trabalhos manuais, economia doméstica ainda existiam nos currículos da Escola Normal em 1890, 1894, 1896, 1911 (ALMEIDA, 1995, 2008; REIS FILHO, 1995), consolidando a formação da mulher no Brasil e voltada para o cuidado com a casa, o marido e os filhos.

Podemos verificar, no Regulamento da Escola Normal de São Paulo de 1887, que a disciplina de Pedagogia e Metodologia incumbia-se de tratar das questões referentes ao trabalho do professor. Quanto à Prática de Ensino, seria realizada na Escola Primária, Anexa à Escola Normal. Não estabelecia vínculo direto com a Escola Normal, porque era organizada e conduzida pelos professores da Escola Primária Anexa. Na Escola Normal, os futuros professores já eram introduzidos na compreensão da educação e do ensino.

Como podemos perceber nos documentos estudados entre o período de 1870 até a Proclamação da República em 1889, a Escola Normal ganhou certo espaço e reconhecimento como local de formação do professor. A Prática do Ensino, antes realizada de forma "artesanal", passa a acontecer em escolas primárias anexas à Escola Normal.

Não é só um local específico, um novo espaço para a realização de exercícios práticos. É uma nova maneira de compreender a formação do professor. Isso ocorre porque as escolas primárias anexas, por serem o espaço de aprendizagem do candidato a professor, começam a preparar-se para realizar essa tarefa.

Se a referência à realização de exercícios práticos na Escola Primária Anexa já estava estabelecida na legislação, como está evidente na Reforma Leôncio Carvalho de 1879, como exposta no Regulamento de 1881 da Escola Normal da Corte ou, ainda, no Regulamento da Escola Normal Paulista de 1887, qual é a efetiva contribuição da Reforma efetivada por Caetano de Campos em 1890 no Estado de São Paulo? Por que essa reforma é considerada um diferencial na formação do professor e na organização da Prática de Ensino?

\section{A Prática de Ensino na institucionalização da Escola Modelo: a organização da Escola Normal no início da República}

No final do século XIX e início do século XX, inúmeras transformações sociais, políticas e econômicas aconteceram no Brasil. Impulsionados por esse novo pensar, para os republicanos, organizar a educação era palavra de ordem.

No período especificado acima, o país efervescia em novas idéias. Entre os educadores, havia a esperança que o novo regime, a República, promovesse a sonhada transformação social por meio da educação. Em pouco tempo, os republicanos sentiram que não era fácil fazer a República. Embora sonhada como um bem, talvez tenha chegado "um pouco mais cedo" (VERÍSSIMO, 1985, p. 41) ou "quase de surpresa" (REIS FILHO, 1995, p. 15) e o envolvimento do povo no projeto republicano não aconteceu de maneira rápida e incondicional. Além disso, os projetos da República não estavam completamente organizados.

$\mathrm{O}$ analfabetismo, considerado entrave nacional, a falta de professores preparados para assumir a educação da nova nação trazia a tona uma questão que perpassava as discussões presentes até então: não seria possível abrir escolas sem ter o professor para nelas atuar.

A formação de professores para educar a população era anseio dos legisladores tanto no período do Império quanto da República. No Império, a preparação de professores nas escolas de ensino mútuo ou em serviço como professores adjuntos, atendia interesses e necessidades daquele momento, ou seja, formação com caráter utilitário. Aprender para fazer. Aprender para ensinar. Aprender na prática. 
Em relação à Escola Normal e mais especificamente sobre a Prática de Ensino, a reforma de São Paulo, dirigida por Caetano de Campos evidenciou a concepção dos republicanos sobre educação e formação de professores. Essa reforma foi considerada modelar para os demais estados da federação.

Essa reforma instituída pelo Decreto $\mathrm{n}^{\circ}$. 27, de 12 de março de 1890, na administração do governador Dr. Prudente J. de Morais Barros. Efetivada por Caetano de Campos 18 provocou entusiasmo nos intelectuais da época. Pelas mudanças que promoveu foi considerada modelar para as demais províncias (REIS FILHO, 1995).

Com a Proclamação da República São Paulo tornou-se centro dos debates políticos e educacionais. Talvez, como evidencia Azevedo (1963, p. 631), porque "foi em São Paulo para onde se deslocou o centro da vida econômica do país, que tomou maior impulso a instrução nos seus diversos graus e modalidades".

Isso pode ter acontecido pelo fato que esta Província subsidiou as políticas imigratórias a partir de 1886. Além disso, as novas perspectivas criadas para os colonos com a abolição do trabalho servil, o desenvolvimento da lavoura cafeeira, que atingiu, em 1895, uma grande alta de preços para o café, foram algumas das causas que atraíram e fixaram um grande número de imigrantes no Estado (AZEVEDO, 1963).

Os debates movimentaram São Paulo e as iniciativas relacionadas com a instrução pública, fora do âmbito do governo, fortaleceram a elite intelectual paulista, conferindo-lhe credibilidade. Foi essa credibilidade que posicionou o Estado de São Paulo com possibilidades de influenciar o pensamento da nação republicana.

A reforma da Escola Normal, considerada como eixo da reforma da instrução pública do Estado de São Paulo, é fator de orgulho e grande importância para os dirigentes da época. Podemos observar nas palavras de Prudente de Morais em 1890 que o ponto fundamental da reforma era que a instrução primária deveria ser "convenientemente ministrada" com professores bem preparados por meio da "educação intellectual, moral e pratica necessária ao bom desempenho". Com esse pensamento, determinou, de certa maneira, as bases da reforma paulista, tomadas como referência por outros estados da federação.

Outra questão a destacar na exposição do Governador é que ele utilizou a idéia de formação prática de forma bastante enfática. Ao referir-se à necessidade de professores bem preparados, especificou que estes, deveriam ser "praticamente instruídos" e que, nas Escolas Normais, "a educação intellectual, moral e pratica" necessária à sua atuação, seria ministrada.

A exposição deixa claro o traço forte da época acerca da Prática de Ensino, o eixo da formação do professor. É interessante notar que Prudente de Morais afirma que realizou a Reforma ouvindo a opinião dos mais competentes. Nesse caso, as indicações mostram tratar-se de Rangel Pestana. A influência de Rangel Pestana na Reforma de Ensino Paulista é evidente19. Essa Reforma expôs os anseios dos republicanos em formar bons mestres. Mestres que pudessem contribuir com a reorganização da instrução primária, considerada, "[...] sem contestação mais forte e efficaz elemento do progresso, e de todos os fatores da instrucção popular", repetindo as palavras de Prudente de Morais, em outubro de 1890.

Nos documentos estudados, percebemos que as escolas primárias anexas à Escola Normal transformam-se em escolas-modelo e ganharam, com isso, espaço, organização, método e credibilidade na formação do professor primário.

Embora ainda se tivesse uma formação quase que exclusivamente na prática, a instituição da Escola-Modelo possibilitou um norte para a formação do professor que, a partir daquele momento, nela se concentrava, diferenciando-se em dois aspectos da formação existente até então: a necessidade de frequência à Escola Normal e certa 
uniformidade de ensino na escola-modelo, local em que os futuros professores poderiam "ver" como os professores ensinavam às crianças.

A Escola-Modelo, criada pelo Decreto de 12 de março de 1890, era destinada à Prática de Ensino para os alunos do $3^{\circ}$ ano da Escola Normal. Nas palavras de Caetano de Campos, "[...] enquanto setor de prática de ensino, a Escola-Modelo é quase autônoma" (REIS FILHO, 1995, p. 54). A afirmação está baseada na estrutura montada para a realização da prática de ensino, ou seja, os alunos eram designados pelo diretor e, sob a inspeção dos professores da Escola-Modelo, executavam o ensino prático.

A vinculação entre os professores da Escola Normal e o ensino prático realizado na Escola-Modelo era, a princípio, mínima. No entanto, a frequência na escola-modelo era obrigatória. As faltas dos alunos tinham as mesmas conseqüências que na Escola Normal, ou seja, inviabilizavam a continuidade dos estudos.

Tamanha foi a responsabilidade atribuída à essa escola na formação do professor por Caetano Campos que, entusiasticamente ele a colocava como chave de toda evolução da formação do professor. Isso possibilita evidenciar três questões em relação à EscolaModelo. Em primeiro lugar, a ênfase na evolução do ensino escolar por meio da formação do professor nessa escola. Em segundo lugar, a importância maior dada à formação prática e modelar, obtida pelos professores por meio dela. Por fim, a consolidação da formação do professor pelo método de ensino intuitivo.

Ao definir a implantação da Escola-Modelo como promotora da evolução do ensino no que se refere à formação do professor, é preciso compreender que, nessa instituição, a formação apresenta-se diferente do que acontecia até então. Ou seja, a organização e estrutura diferem do modelo "artesanal" que foi marcado pelo aprendizado do método mútuo, ou pela formação pretendida pelos professores adjuntos.

$\mathrm{Na}$ perspectiva da reforma instituída por Caetano de Campos, a Escola Modelo foi organizada de forma a garantir o aprendizado da função de professor. Além de estar adequadamente mobiliada e com material necessário, os professores que nela atuavam eram reconhecidamente bons professores, ou seja, modelos.

O cuidado com a implementação das ações que eram desenvolvidas na EscolaModelo fortaleceu a sua estrutura e intenção, considerando que, na pedagogia moderna, a arte de ensinar era extremamente prática, ou seja,

[...] no âmbito dessa pedagogia, ensinar a ensinar é fornecer esses modelos, seja na forma de roteiros de lições, seja na forma de práticas exemplares cuja visibilidade é assegurada por estratégias de formação docente, preferencialmente dadas a ver em Escolas Modelo, anexas às Escolas Normais (CARVALHO, 2000a, p. 113).

Entretanto, o modelo de formação do professor pensado por Caetano de Campos, com a institucionalização da Escola-Modelo, não tinha apenas uma conotação de formação na prática, como acontecia na formação por meio do método de ensino mútuo ou, no caso dos professores adjuntos. Ao realizar a Prática de Ensino na Escola Modelo, o aluno do terceiro ano da Escola Normal entrava em contato com o trabalho de um professor da Escola-Modelo, e era por ele orientado e supervisionado. Esse professor era encarregado da formação prática desse aluno.

Cabia ao aluno da Escola Normal na Prática de Ensino observar atentamente o trabalho do professor e anotar as suas observações. Durante duas horas diárias, o aluno realizava observação da prática de um professor experiente. Com isso, o aluno-mestre apreendia por meio da observação, para, depois, reproduzir o que havia aprendido na direção de classe. 
No currículo da Escola Normal de 1890, na terceira série, além da disciplina de Organização das Escolas e sua Direção, aparecem os Exercícios Práticos. Estes eram realizados na Escola-Modelo. Na primeira e segunda série, entretanto, não havia nenhuma disciplina de formação. As disciplinas apresentavam um caráter utilitário de cunho humanístico (ALMEIDA, 1995).

As questões apresentadas nos levam a concordar que "no decorrer do século XIX assistimos, então, ao processo gradual de organização da educação das crianças passando do ensino individual para o mútuo, deste para o simultâneo e finalmente para o ensino intuitivo" SAVIANI (2006, p. 28). Com a formação do professor pode-se estabelecer o mesmo percurso e aqui há uma questão muito importante. Aprender o método era a condição para ser professor.

\section{Considerações finais}

A criação e consolidação da Escola Normal como local apropriado para a formação do professor ganhou espaço e efervescência juntamente com as discussões acerca da República, da construção de um país democrático e da cidadania. A idéia de democracia defendida pelos republicanos tornava necessária uma nova discussão acerca da formação de um professor capaz de veicular essas idéias.

Assim, a reforma da Escola Normal pós República foi o primeiro passo para a reforma do ensino especialmente o primário que seria naquele momento o veículo de mudanças e concretização do ideal republicano. As discussões em torno da necessidade de formar o professor para as novas necessidades do país republicano, remetem a questionamentos quanto ao que seria necessário em sua formação. A Escola Normal ganhou um currículo mais amplo. O reconhecimento pelos estudos ali organizados fortaleceu a instituição como local de formação do futuro professor.

A Prática de Ensino adquiriu novos contornos na Escola Modelo. A formação por meio da Prática do Ensino ou do modelo "artesanal" foi substituída, dessa forma, pela formação na Prática de Ensino ancorada nos estudos que os futuros professores desenvolviam na Escola Normal.

A vinculação da formação prática do professor à Escola Modelo e aos conhecimentos adquiridos na Escola Normal fortaleceu a necessidade de formação específica para ser professor. Começava a delinear-se um lócus de formação do professor primário, a Escola Normal.

\section{REFERÊNCIAS}

ARIÈS, Philippe. O tempo da história. Rio de Janeiro: Francisco Alves, 1981.

ALMEIDA, Jane Soares de. Currículos da Escola Normal Paulista (1846-1920): Revendo uma Trajetória. Revista Brasileira de Estudos Pedagógicos. Brasília, v. 76, n. 184, p. 665-689, set. dez. 1995.

ALMEIDA, Jane Soares de. Mulheres na educação: missão, vocação e destino? A feminização do magistério ao longo do século XX. In: In: SAVIANI, Dermeval. et al. O legado educacional do século XX no Brasil. 2. ed. Campinas, SP: Autores Associados, 2006. p. 59-107. 
ALMEIDA, José Ricardo Pires de. Instrução pública no Brasil (1500-1889): história e legislação. Trad. Antonio Chizzotti; ed. Critica Maria do Carmo Guedes. 2. ed. rev. São Paulo: EDUC, 2000.

AZEVEDO, Fernando. A cultura brasileira. Introdução ao estudo da cultura no Brasil. 4. ed. revista e ampliada. Brasília, DF: Editora Universidade de Brasília, 1963.

BARBOSA, Rui. Obras Completas. 1883. v. X. tomo III. Reforma do ensino primário e várias instituições complementares da instrução pública.

BASTOS, Maria Helena Câmara; FARIA FILHO, Luciano Mendes. (org.). A escola elementar no século XIX: o método monitorial/mútuo. Passo Fundo RS: Ediupf, 1999a.

BASTOS, Maria Helena Câmara. O ensino mútuo no Brasil (1808-1827). In: BASTOS, Maria Helena Câmara; FARIA FILHO, Luciano Mendes. (Org.). A escola elementar no século XIX: o método monitorial/mútuo. Passo Fundo RS: Ediupf, 1999b. p. 95-118.

BRASIL. Lei de 15 de outubro de 1827. Disponível em <WWW.soleis.adv.br $>$. Acesso em 16 mar. 2007.

BRASIL. Decreto n. 1331 A, de 17 de fevereiro de 1854. Approva o regulamento para a reforma do ensino primário e secundário no Município da Corte. Disponível em: <http://www2.camara.gov.br/legislação/publicacoes/doimperio>. Acesso em 10 mar. 2008.

CARVALHO, Marta Maria Chagas. Modernidade Pedagógica e modelos de formação docente. São Paulo em Perspectiva. São Paulo, v. 14, n. 1, p. 111-120, 2000a.

CARVALHO, Marta Maria Chagas. Reformas da instrução pública. In: LOPES, Eliane Marta Teixeira; FARIA FILHO, Luciano Mendes; VEIGA, Cynthia Greive. (Orgs.). 500 anos de educação no Brasil. 2. ed. Belo Horizonte: Autêntica, 2000b. p. 225 - 252.

EXPOSIÇÃO apresentada ao Dr. Jorge Tibiriçá pelo Dr. Prudente J. de Morais Barros, ao passar-lhe a administração no dia 18 de outubro de1890. Disponível em: $<$ http://brazil.crl.edu/bsd/bsd>. Acesso em: 05 jun. 2008.

FALA DO PRESIDENTE DA PROVÍNCIA do Rio de Janeiro, Conselheiro José Rodrigues Torres em 01 de fevereiro de 1835. 1.a sessão da 1.a legislatura da Assembléa Legislativa da mesma província. Nictheroy, Typ. de Amaral \& Irmão, 1850. Disponível em: <http://brazil.crl.edu/bsd>. Acesso em 20 abr. 2008.

GONDRA, José Gonçalves; SACRAMENTO, Winston. Luiz Pedreira do Coutto Ferraz. In: FÁVERO, Maria de Lourdes de Albuquerque. BRITTO, Jader de Medeiros. Dicionário de educadores no Brasil da colônia aos dias atuais. 2 ed. aum. Rio de Janeiro Editora UFRJ/MEC-Inep-Comped, 2002. p.723 -730.

HILSDORF, Maria Lúcia Spedo. Francisco Rangel Pestana: jornalista, político, educador. Tese. (Doutorado em Educação) Universidade de São Paulo, 1996.

HILSDORF, Maria Lúcia Spedo. Francisco Rangel Pestana: jornalista, político, educador. Tese. (Doutorado em Educação). Faculdade de Educação. Universidade de São Paulo, 1986.

Revista HISTEDBR On-line, Campinas, número especial, p. 227-245, mai.2010 - ISSN: 1676-2584 242 
HOBSBAWM, Eric. Sobre história. São Paulo: Cia das Letras, 1998.

MIGUEL, Maria Elizabeth Blanck. A escola normal do Paraná: instituição formadora de professores e educadora do povo. In: ARAÚJO, José Carlos Souza; FREITAS, Anamaria Gonçalves Bueno de; LOPES, Antônio de Pádua Carvalho. (Orgs.) As escolas normais no Brasil: do império à república. Campinas, SP: Alínea, 2008. p. 145-162.

NASCIMENTO, Maria Isabel Moura. A primeira escola de professores dos Campos Gerais - PR. Tese. Doutorado em Educação. Universidade Estadual de Campinas. Faculdade de Educação. Campinas, SP, 2004.

NEVES, Fátima Maria. O Método lancasteriano e o projeto de formação disciplinar do povo. (São Paulo 1808 - 1889). 293f. Tese (Doutorado em História). Universidade Estadual Paulista, Assis, SP, 2003.

NEVES, Fátima Maria. Investigação em torno do método lancasteriano ou do ensino mútuo (Contribuições para a produção do Estado da Arte em História da Educação no período Imperial. Comunicações, 2005a.

NEVES, Fátima Maria. A instrução pública, o método pedagógico de Lancaster e a instituição do estado nacional. In: ROSSI, Ednéia; RODRIGUES, Elaine; NEVES, Fátima Maria. (Orgs.). Fundamentos históricos da educação no Brasil. Maringá, PR: EDUEM, 2005b.

NEVES, Fátima Maria . O método lancasteriano e o ensino da ordem e da disciplina para os soldados do império brasileiro. In: 30 ${ }^{\mathbf{a}}$ Reunião da ANPED, 2007, Caxambu. Anais da 30ª Reunião da ANPED. Caxambu: Editora da ANPED, 2007. v. 1. p. 1-10.

RELATÓRIO apresentado à Assembléia Legislativa do Paraná pelo Presidente da Província, Polidoro Cezar Burlamaque. Curitiba, Typ de Candido Martins Lopes, 1867. Disponível em: <http://brazil.crl.edu/bsd/bsd/629/index.html >. Acesso em: 18 mar. 2008.

REIS FILHO, Casemiro dos. A educação e ilusão liberal: origens do ensino público paulista. Campinas. SP: Autores Associados, 1995.

ROSIN, Sheila Maria. Escolas Normais e formação de professores para o ensino fundamental: alguns aspectos históricos (1854-1889). Revista Teoria e Prática da Educação. v. 8, n. 2, p. 209-216. mai. ago. 2005.

SANTONI RUGIU, Antonio. Nostalgia do mestre artesão. Campinas, SP: Autores Associados, 1998.

SAVIANI, Dermeval. Educação e colonização: as idéias pedagógicas no Brasil. BASTOS, Maria Helena Câmara. (Org.). Histórias e memórias da Educação. Petrópolis, RJ: Vozes, 2004.

SAVIANI, Dermeval. História da fomação docente no Brasil: três momentos decisivos. Revista do Centro de Educação. Edição: 2005 - v. 30. n. 02. Disponível em: $<$ WWW.ufsm.br/ce/revista $>$. Acesso em: 28 mai. 2006. 
SAVIANI, Dermeval. O legado educacional do breve século XIX brasileiro. In: SAVIANI, Dermeval. et al. O legado educacional do século XIX no Brasil. 2. ed. Campinas, SP: Autores Associados, 2006. p. 7-32.

SAVIANI, Dermeval. História das idéias pedagógicas no Brasil. Campinas. SP: Autores Associados, 2007.

SCHELBAUER, Analete Regina. A constituição do método de ensino intuitivo na província de São Paulo (1870 - 1889). Tese. (Doutorado em Educação). Faculdade de Educação da USP, São Paulo, 2003.

SCHELBAUER, Analete Regina. O método intuitivo e lições de coisas: saberes em curso nas conferências pedagógicas do século XIX. Artigos. Navegando na História da Educação Brasileira. HISTEDBR, 2006a. Disponível em: <http://www.histedbr.fae.unicamp.br/navegando/artigos>. Acesso em: 10 jan. 2008.

TANURI, Leonor Maria. História da formação de Professores. Revista Brasileira de Educação. Associação Nacional de Pesquisa em Educação. São Paulo, n. 14, maio - ago. 2000 .

VERÍSSIMO. José. A educação nacional. 3. ed. Porto Alegre: Mercado Aberto, 1985.

VIDAL, Diana Gonçalves; FARIA FILHO, Luciano Mendes de. Reescrevendo a história do ensino primário: o centenário da lei de 1827 e as reformas de Francisco Campos de Fernando de Azevedo. In: VIDAL, Diana Gonçalves; FARIA FILHO, Luciano Mendes de. As lentes da história. Campinas, SP: Autores Associados, 2005. p. 7-39.

VILELLA, Heloisa. A primeira escola normal do Brasil. In: NUNES, Clarice (Org.). O passado sempre presente. São Paulo: Cortez, 1992. p. 17-42. (Questões da nossa época: v. 4).

VILLELA, Heloisa de Oliveira S. Da palmatória à lanterna mágica: a escola normal da província do Rio de Janeiro entre o artesanato e a formação profissional (1868-1876). Tese. (Doutorado em Educação) - FE/USP, 2002.

VILLELA, Heloisa de Oliveira S. Do artesanato à profissão: saberes de normalistas no Brasil do século XIX. ANPED: GT: História da Educação/n.02. Poços de Caldas: MG, 2003. Disponível em: <http://189.1.169.50/reunioes/26/trabalhos. Acesso em: 23 abr.2008.

\footnotetext{
${ }^{1}$ Mestre em Educação pela Universidade Estadual de Maringá.

${ }^{2}$ Doutora em Educação, Professora do Programa de Pós-Graduação em Educação da Universidade Estadual de Maringá.

${ }^{3}$ Dentre outras questões, a escolha da data em comemoração ao "Dia do professor" está relacionada à Lei de 15 de Outubro de 1827. (NEVES, 2005b). Duas reformas educacionais importantes foram promulgadas no contexto da comemoração do centenário da Lei de 1827: a reforma organizada por Francisco Campos, em Minas Gerais, em 15 de outubro de 1927, e a reforma do Distrito Federal, apresentada como projeto por Fernando de Azevedo, em 22 de outubro de 1927. Sobre essa questão indicamos Vidal e Faria Filho (2005).

${ }^{4}$ O modelo artesanal, próprio das corporações de ofício, está relacionado ao "aprender fazendo". (SANTONI RUGIU, 1998).

${ }^{5}$ Em 1835, Minas Gerais também cria uma Escola Normal, cuja implantação ocorreu somente em 1840.

${ }^{6}$ O Relatório em questão foi apresentado à Assembléia Legislativa do Paraná em 15/03/0867.
} 
${ }^{7}$ É constante a referência a esta frase ligada quase sempre ao insucesso da Escola Normal no século XIX. Tanuri (2000) e Villela (2003) utilizam-na para analisar os fatores de instabilidade das escolas normais; Rosin (2005) também utiliza essa expressão ao analisar a Escola Normal na Província do Paraná. Nascimento (2004, p. 57) transcreve a parte do Relatório do Presidente da Província do Paraná de 1867 em que faz referência à célebre analogia, chamando a atenção para a indefinição em relação à necessidade de incentivos quanto à carreira do Magistério, bem como ao financiamento e manutenção das Escolas Normais. Miguel (2008) ao analisar o posicionamento do Presidente da Província, bem como sua visão acerca das pessoas que escolhiam a carreira do magistério, destaca que, para ele, só acontecia quando os candidatos não encontravam nada mais para fazer.

8 A segunda hipótese trata da necessidade que o novo professor, formado na Escola Normal, tinha de relacionar-se com as novas formas de poder da sociedade; a terceira hipótese trata da forma com que aconteceu a apropriação concreta de alguns modelos de formação de professores em circulação, naquele momento, na Europa e Estados Unidos, com adaptação específica à realidade brasileira e não como mera cópia, para suprir a necessidade do momento; a quarta hipótese trata do período de transição que a Escola Normal viveu com avanços e retrocessos (VILLELA, 2002; 2003).

${ }^{9}$ Há referências quanto à implantação de Escolas de Ensino Mútuo no Brasil antes de 1827 de acordo com Almeida (2000), Bastos (1999a), Saviani (2007).

${ }^{10}$ No entendimento de Bastos (1999b), o método foi sistematizado separadamente por Andrew Bell (17531832), pastor da Igreja Anglicana, e Joseph Lancaster (1778-1838), membro da seita dos Quakers. Neves (2003; 2005a; 2005b; 2007) faz um esclarecimento importante sobre o Método Lancasteriano, conhecido e confundido com o Método Monitorial ou do Ensino Mútuo. "Esse método ficou conhecido como Método de Ensino Mútuo, Método Monitorial, Método Inglês de Ensino, Método Lancasteriano de Ensino e também como Sistema de Madras" (NEVES, 2003, p. 63, grifos da autora). Isso aconteceu de acordo com as regiões onde foi instituído.

${ }^{11}$ Trata-se da obra de José Ricardo Pires de Almeida, cuja primeira edição é de 1889 e foi publicada em francês. Utilizamos, nesta pesquisa, a edição de 2000, traduzida por Antonio Chizzotti.

${ }^{12}$ Em Portugal, também aconteceu essa prática (BASTOS, 1999b).

${ }^{13}$ NEVES (2007) faz a constatação ao analisar o "Projeto sobre o estabelecimento e organisação da Instrucção Publica no Brazil", de autoria do General Francisco de Borja Garção Stocker, e a "Memória sobre a Reforma dos estudos na Capitania de São Paulo, de Martin Francisco Ribeiro d' Andrada Machado. Nesses documentos, a referência é sempre ao Método Lancasteriano e estão evidentes os princípios definidos e defendidos por Lancaster.

14 Considerando como local específico a Escola Normal, há que se lembrar que a primeira Escola Normal no Brasil foi criada somente em 1835 na Província do Rio de Janeiro.

${ }^{15}$ Trata-se da obra "A educação Nacional”, de José Veríssimo, que teve a primeira edição publicada em 1890. A referência aqui utilizada é a terceira edição, publicada em 1985.

${ }^{16}$ Almeida (2000, p. 91) faz referência à instituição e nomeação dos professores adjuntos referindo-se ao Decreto n. 1331 A, de 17 de fevereiro de 1854. Saviani (2007, p. 133 - 136) analisa as condições de contratação dos professores adjuntos.

${ }^{17}$. Esta citação consta do tópico Formação do professorado: Escolas Normais, nas Obras Completas. Volume X,Tomo III, de Rui Barbosa, 1883.

${ }^{18}$ Antonio Caetano de Campos, médico, nomeado diretor da Escola Normal de São Paulo por Prudente de Morais, por indicação de Rangel Pestana, com o objetivo de colocar em prática a reforma da Escola Normal, considerada a primeira fase da reforma de ensino paulista. Essa Reforma teve sua efetivação entre janeiro de 1890 e setembro de 1891, porque a morte prematura de Caetano de Campos, em 12 de setembro de 1891, deixou sua obra apenas iniciada. A Reforma paulista de 1890 foi amplamente estudada por Reis Filho (1995).

${ }^{19}$ Sobre esse assunto indicamos: Hilsdorf (1986) Reis Filho (1995); Schelbauer (2003).

Artigo recebido em: 25/04/2010

Aprovado para publicação em: 08/06/2010 